\title{
OS SETORES PÚBLICO E PRIVADO NO PROCESSO DE INOVAÇÃO NO TRANSPORTE DE RESÍDUOS SÓLIDOS POR INTERMÉDIO DO CAVALO ELÉTRICO
}

\author{
OF THE PUBLIC AND PRIVATE SECTORS IN THE PROCESS OF \\ INNOVATION IN THE TRANSPORT OF SOLID FOR THE INTERMEDIATE OF THE ELETRIC HORSE
}

\author{
Angela Cassia Costaldello ${ }^{1}$ \\ Angelica Ferreira Rosa²
}

\section{RESUMO}

O presente artigo tem como objetivo apresentar o projeto de vanguarda, o "cavalo elétrico", como possível substituição das carroças, charretes e carrinhos para coleta e transporte de lixo reciclável no Município de Guarapuava, Paraná. A proposta foi desenvolvida por uma Empresa Júnior mediante parceria do setor público e a iniciativa privada, objetiva a construção de carros de coleta de tração elétrica como substituição para os profissionais de coleta e reciclagem de lixo e é objeto de projeto de lei municipal a ser apresentado ao Legislativo municipal, a fim de promover o bem estar animal ao substituir, de maneira sustentável, os veículos de tração animal. Essa iniciativa encontra respaldo nos objetivos da Organização das Nações Unidas que entende que o desenvolvimento sustentável está apoiado em três pilares, o econômico, o social e o ambiental, por isso, o mesmo tem o condão de atender de cada um desses setores, demonstrando a indispensabilidade do projeto de lei municipal que, depois de aprovado, deverá ser implantado pela Administração Pública de Guarapuava.

\footnotetext{
${ }^{1}$ Professora de Direito Administrativo e Urbanístico do Departamento de Direito Público da Faculdade de Direito e do Programa da Pós-graduação em Direito da UFPR. Especialização pela Facoltà di Giurisprudenza della Università Statale di Milano (1995/96), Mestrado (1990) e Doutorado (1998) pela Faculdade de Direito da Universidade Federal do Paraná. Coordenadora do Núcleo de Estudos de Direito Administrativo, Urbanístico, Ambiental e Desenvolvimento - PRO POLIS, vinculado do Programa de Pós-graduação da Faculdade de Direito da UFPR.Visiting Fellow na Università degli Studi di Palermo (Itália). Advogada. Professora de Direito Administrativo e Urbanístico do Departamento de Direito Público da Faculdade de Direito e do Programa da Pós-graduação em Direito da UFPR. Brasil. E-mail: acostadello@hotmail.com

2 Doutorado em andamento na Universidade Federal do Paraná 2016 na área de concentração Relações Sociais, linha de pesquisa Novos Paradigmas do Direito e orientação do Doutor Elimar Szaniawski. Mestrado concluso na qualidade de bolsista na área dos Direitos de Personalidade, na linha de pesquisa Instrumentos de Efetivação dos Direitos da Personalidade pelo Centro Universitário de Maringá-Unicesumar. Universidade Federal do Paraná - UFPR, Paraná. Brasil. E-mail: angelicaferreirarosa@hotmail.com
} 
Palavras-chave: Sustentabilidade. Carro de Tração Elétrica. Administração Pública. Direitos dos Animas.

\section{ABSTRACT}

The objective of this article presents the avant garde project, the "electric horse", as a possible substitution of carts, carts and trolleys for collecting and transporting recyclable garbage in the municipality of Guarapuava, Paraná. The proposal was developed by a Junior Company through a partnership of the public sector and the private initiative, aims to build electric traction collection cars as a substitute for professionals in garbage collection and recycling and is the subject of a municipal bill in order to promote animal welfare by substituting livestock vehicles in a sustainable way. This initiative is supported by the objectives of the United Nations Organization, which believes that sustainable development is supported by three pillars economic, social and environmental and therefore it has the capacity to serve from each of these sectors, demonstrating the indispensability of the municipal bill that, once approved, shall be implemented by the Guarapuava Public Administration.

KEYWORDS: Sustainability; Electric Traction Cart; Public administration; Animal Rights;

\section{INTRODUÇÃO}

O projeto "Cavalo Elétrico" visa a substituição de carroças, charretes e carrinhos que os catadores de lixo utilizam para a coleta e o transporte dos resíduos sólidos, o qual foi desenvolvido pela Universidade Tecnológica Federal do Paraná (UTFPR), com o apoio do Poder Legislativo do Município de Guarapuava, ainda em vias de ser apresentado o projeto de lei, em parceria com a iniciativa privada ${ }^{3}$, cuja empresa se dedica à construção de carros para coleta de tração elétrica.

O projeto, com algumas fases já concretizadas, servirá de sustentáculo para o projeto de lei na Câmara Municipal de Guarapuava que, após aprovado, será implantado pela Administração Pública. ${ }^{4}$

Tal empreendimento foi criado para que haja o desenvolvimento sustentável, o qual está apoiado nos três pilares: o econômico, o social e o ambiental. Nesse passo, merece ser ressaltado o pilar social, voltado ao aspecto sanitário, nele inseridos os agentes que promovem a coleta, para posterior reciclagem, ou seja, cada trabalhador atua como "operador ecológico".

Os referidos "agentes sanitários", na maioria das vezes, vistos como pessoas à margem da sociedade e, por conseguinte, marginalizados; têm suas relações de trabalho precárias, o 
trabalho é mal remunerado, pouco reconhecido, o que provoca um sentimento de inutilidade no trabalhador, com a instabilidade do emprego, a ameaça do desemprego, a restrição dos direitos sociais e a falta de perspectiva de crescimento profissional do setor informal. ${ }^{5}$

Essa categoria constou pela primeira vez na Classificação Brasileira de Ocupações - CBO ${ }^{6}$ como categoria profissional de catador de material reciclável, fato que propiciou a melhoria na identificação desses trabalhadores, os quais antes eram identificados por outras nomenclaturas até mesmo pejorativas. ${ }^{7}$

Outra consequência benéfica será a de permitir uma análise social mais adequada e precisa desses cidadãos no território nacional, com base nos dados do Censo Demográfico de 2010 (IBGE, 2012), não obstante mereça registro o fato de que tais pesquisas são domiciliares e auto declaratórias, o que induz a insegurança na prestação dessas informações, além de que essas pessoas que exercem a atividade de coleta do material reciclável não possuem domicílio fixo definido. $^{8}$

No Diagnóstico sobre catadores de resíduos sólidos desenvolvido pelo Ipea (2011), estimou-se, com base em dados de organizações públicas empresarias e do próprio Movimento Nacional dos Catadores Recicláveis, um intervalo entre 400 e 600 mil catadoras e catadores no país, ou seja, um número alarmante de pessoas que precisam receber condições mínimas de salubridade, conforto e alimentação.

Para exercer a atividade, muitas vezes esses trabalhadores transportam até toneladas de materiais para a reciclagem em carroças, charretes e carrinhos. Frequentemente quem carrega o excesso de peso é o próprio trabalhador que sofre sérias consequências em sua saúde por caminhar quilômetros com materiais recicláveis e demais unidades de pequeno volume (como entulhos, pneus, lixo doméstico descartado), também são vítimas de graves acidentes (como, por exemplo, a quebra da mandíbula pela batida do carrinho na boca do trabalhador).

Nas carroças ou charretes, quem puxa a carga é o animal de tração, em geral equinos, que, segundo Mariângela Freitas de Almeida e Souza, estima-se que existam em torno de 300 milhões de animais de tração, utilizados por dois bilhões de pessoas, em cerca de 30 países $^{9}$. Esses animais são submetidos a ambientes que, de modo algum, estão em condições de bem-estar mínimo, beirando à crueldade.

Neste sentido, a Constituição Federal do Brasil de 1988, no art. 225 ${ }^{10}$, proíbe práticas que submetam os animais à crueldade, e a Lei dos Crimes Ambientais (Lei $n^{\circ}$ 9.605/1998 ${ }^{11}$ ), art. 32, transformou em crime o ato de praticar abusos, maus-tratos, ferir ou mutilar animais de 
quaisquer espécies, com pena de detenção, de três meses a um ano, e multa, ressaltando que a pena é aumentada de um sexto a um terço se ocorrer morte do animal. ${ }^{12}$

O projeto de lei, objeto que compõe esse texto, visa à substituição desses animais e facilitar o trabalho das pessoas que carregam essas cargas. É uma solução que tem o condão de proteger os seus direitos, pois a substituição por veículos automotores, recarregáveis por meio de bateria, com estrutura apta para carregar até $600 \mathrm{~kg}$ de materiais, para os quais não é necessário o uso de carteiras de motoristas, com limite de velocidade que é de $6 \mathrm{~km} / \mathrm{h}$. O trabalhador ficaria ao lado do protótipo, o qual seria distribuído pela Prefeitura de Guarapuava, a responsável por garantir a devida manutenção e sinalização.

\section{SUSTENTABILIDADE}

É indispensável a definição do que seria o desenvolvimento sustentável. Toma-se como referencial e definição da Comissão Mundial sobre Meio Ambiente e Desenvolvimento (WCED): "desenvolvimento sustentável é o desenvolvimento que satisfaz as necessidades do presente sem comprometer as habilidades das futuras gerações de satisfazerem suas necessidades" ${ }^{13}$

Elimar Pinheiro do Nascimento ${ }^{14}$ salienta que o desenvolvimento sustentável possui origem econômica "em face da percepção crescente ao longo do século XX de que o padrão de produção e consumo em expansão no mundo, sobretudo no último quarto desse século, não tem possibilidade de perdurar". ${ }^{15}$

A Comissão Mundial sobre Meio Ambiente e Desenvolvimento (WCED) adota objetivos críticos que derivam do conceito de desenvolvimento sustentável. São eles: ${ }^{16}$
1. crescimento renovável;
2. mudança de qualidade do crescimento; água e saneamento básico;
4. garantia de um nível sustentável de população;
5. conservação e proteção da base de recursos;
6. reorientação da tecnologia e gerenciamento do risco;
7.reorientação das relações econômicas internacionais.

3.satisfação das necessidades essenciais por emprego, comida, energia,

Georgete Nacarato Nako e Toshio Mukai afirmam que foi somente na década de 60, graças à forte influência da opinião pública internacional, que se iniciou, por parte das 
autoridades competentes, a preocupação com o estado geral do meio ambiente, pois nesse período ocorreu o surgimento de leis internas no mundo inteiro, na tentativa de se criar legislações internacionais capazes de estabelecer critérios válidos para combater a poluição das águas, do ar, solo, de todo a fauna e a flora.

Assim, estabeleceu órgãos administrativos especiais, ministérios ou agências internacionais-governamentais e órgãos descentralizados e também disposições internas dos Estados e textos internacionais referentes à preservação ambiental, inclusive no Brasil nas décadas de 30 e 40 apresentou os códigos específicos para florestas, minas e águas ${ }^{17}$.

A noção de sustentabilidade está atrelada à escassez dos recursos naturais, os quais estão entrelaçados a ideia de desenvolvimento que, de acordo com a Conferência das Nações Unidas sobre o Meio Ambiente Humano, reunida em Estocolmo de 5 a 16 de junho de 1972, pela necessidade de critério e princípios comuns, com o objetivo de preservar e melhorar o meio ambiente humano. ${ }^{18}$

O desenvolvimento do homem está conexo com a sustentabilidade em uma relação de equilíbrio entre o meio ambiente natural e artificial, para que, por meio daquele, seja alcançado o pleno bem-estar do homem. A proteção e o melhoramento do meio ambiente humano são considerados pela Declaração de Estocolmo sobre o meio ambiente humano uma questão fundamental que afeta a todos indistintamente. Mesmo com o nascimento dessa nova noção de desenvolvimento que também está inserida na Rio (1992), a humanidade na atualidade continua destruindo o meio ambiente em relação ao consumo dos limites de recursos disponíveis por ano, como se compreende na notícia ${ }^{19}$ :

A associação ambientalista Zero revelou esta terça-feira que a partir da próxima quarta-feira a humanidade atinge o limite de recursos disponíveis para este ano, mais cedo do que em 2016, quando este marco foi ultrapassado a 8 de Agosto. De acordo com a Zero, o último ano em que a humanidade respeitou o "orçamento natural anual", fazendo com que os recursos existentes no planeta chegassem para o ano inteiro, foi há quase 50 anos, em 1970. A Zero sublinha também o peso da pegada ecológica de Portugal, lembrando que eram precisos mais do que um planeta, se todos os países atingissem os níveis portugueses. "Se todos os países tivessem a mesma pegada ecológica que nós, seriam necessários 2,3 planetas", lembra. Para os ambientalistas da Zero, o consumo de alimentos (32\% da pegada global do país) e a mobilidade (18\%) são as atividades humanas diárias que mais contribuem para a pegada ecológica de Portugal. "Num mundo onde persiste uma enorme desigualdade em termos de distribuição de rendimentos e acesso a recursos naturais, estes dados são claros sobre a necessidade de se produzir e consumir de forma muito diferente", defendem. Grifos nossos 
Em 1968, a Convenção Africana para conservação da natureza e dos recursos naturais, que substituiu a Convenção de Londres de 1933 firmada entre os países colonizadores, é um modelo de princípios que demonstram a preocupação mundial com a sustentabilidade.

A Declaração Universal de Direitos do Homem (ONU, 1948) e a Declaração Americana dos Direitos e Deveres do Homem, que são soft law, ou seja, não apresentam força coercitiva. A Convenção Americana sobre Direitos Humanos de São José da Costa Rica, 1969, e os Pactos Internacionais de Direitos Econômicos, Sociais e Culturais e Direitos Civis e Políticos 1966 asseguraram as condições consideradas mínimas de desenvolvimento que cada vez mais melhoram as relações do homem com a natureza e o ambiente.

Sobre a preocupação com a sustentabilidade dos recursos naturais presente na evolução histórica dos documentos internacionais referente à proteção ao meio ambiente, recentemente a associação ambientalista Zero trouxe informações atuais do mês de agosto do ano 2017. Tratase do fato da humanidade ter atingido os limites de recursos disponíveis do presente ano que evidenciaram a indispensabilidade de uma mudança em relação à produção e consumo que precisa ser diferente. Dentre várias propostas, a associação apresentou ${ }^{21}$ :

Entre as várias propostas da Zero para reduzir o défice ambiental está a aposta numa economia circular, em que "a utilização e reutilização de recursos é maximizada" e que segundo os ambientalistas deverá ser "uma prioridade transversal a todas as políticas públicas". "O ponto fulcral deverá ser a redução no uso de materiais, a promoção da reutilização e a extensão dos tempos de vida dos bens e equipamentos. Para ser eficaz, teremos de mudar o paradigma de 'usar e deitar fora', muito assente na reciclagem, incineração e deposição em aterro, para um paradigma de 'ter menos, mas de melhor qualidade'", defende a associação. Grifos nossos

As possibilidades apresentadas pela Associação e o entendimento do que significa o desenvolvimento sustentável, tem-se que a utilização do projeto "Cavalo Elétrico" é importante e funciona como possível solução para o desenvolvimento sustentável, pois ajudará a conservação do meio ambiente com a reutilização e a extensão do tempo de vida dos carrinhos que apresentam duração prolongada em relação a carroças e charretes utilizadas pelos catadores de materiais recicláveis. Ou seja, vão agredir menos o meio ambiente e melhorarão a condição social dessas pessoas que receberão e terão a manutenção desses carrinhos gratuitamente, pela administração pública da cidade de Guarapuava, no Estado do Paraná, em consonância com o cuidado dos animais.

Estes são utilizados na tração de veículos, infelizmente, sofrem com o ambiente em que são expostos e também com a forma pela qual são conduzidos, o que consequentemente gera a 
inadaptação em relação à anatomia e à fisiologia, dificultando até mesmo o próprio andamento das atividades; afinal, são expostos a horas exaustivas de trabalho, a uma sobrecarga considerável, a castigos imoderados, a falta de alimentação, a privação de água, a ausência de cuidados com a saúde, higiene, etc ${ }^{22}$.

\section{DIREITOS DOS ANIMAIS}

Os animais sempre foram considerados objetos que serviam para satisfazer as necessidades humanas. Porém, a doutrina tem Ihes dado o status de sujeitos de direitos. O Código Civil de 2002 define dois tipos de natureza jurídica: de pessoas ou de coisas. As coisas são consideradas como bens móveis, suscetíveis de movimento próprio, ou de remoção por força alheia, sem alteração da substância ou da destinação econômico social. ${ }^{34}$

Para a Medicina Veterinária, ${ }^{35}$ é indispensável que os animais sejam tratados com dignidade. Logo, a saúde física é condição necessária para que os animais possam trabalhar e viver. Esse significado, porém, não se limita somente à condição física, como a ausência de doenças, mas também à inclusão do estado do bem-estar animal.

Com efeito, sobre a proclamação dos Direitos dos Animais, tem-se que a Organização das Nações Unidas para a Educação, a Ciência e a Cultura (UNESCO) promulgou os Direitos dos Animais que já no preâmbulo dispõe que todo animal possui direitos. Desse modo, quando há o desconhecimento e o desprezo desses direitos, ocorrem por parte do homem o acometimento de crimes e o desrespeito à natureza, pois o respeito do homem pelos animais está ligado ao respeito do homem ao seu semelhante. Ainda proclama, em seus quatorze artigos, os direitos dos animais, in verbis: ${ }^{36}$

ARTIGO 1:

Todos os animais nascem iguais diante da vida, e têm o mesmo direito à existência.

ARTIGO 2:

a) Cada animal tem direito ao respeito.

b) O homem, enquanto espécie animal, não pode atribuir-se o direito de exterminar os outros animais, ou explorá-los, violando esse direito. Ele tem o dever de colocar a sua consciência a serviço dos outros animais. 
c) Cada animal tem direito à consideração, à cura e à proteção do homem. ARTIGO 3:

a) Nenhum animal será submetido a maus-tratos e a atos cruéis

b) Se a morte de um animal é necessária, deve ser instantânea, sem dor ou angústia. ARTIGO 4:

a) Cada animal que pertence a uma espécie selvagem tem o direito de viver livre no seu ambiente natural terrestre, aéreo e aquático, e tem o direito de reproduzir-se.

b) A privação da liberdade, ainda que para fins educativos, é contrária a este direito.

ARTIGO 5:

a) Cada animal pertencente a uma espécie, que vive habitualmente no ambiente do homem, tem o direito de viver e crescer segundo o ritmo e as condições de vida e de liberdade que são próprias de sua espécie.

b) Toda a modificação imposta pelo homem para fins mercantis é contrária a esse direito.

ARTIGO 6:

a) Cada animal que o homem escolher para companheiro tem 0 direito a uma duração de vida conforme sua longevidade natural

b) O abandono de um animal é um ato cruel e degradante.

ARTIGO 7:

Cada animal que trabalha tem o direito a uma razoável limitação do tempo e intensidade do trabalho, e a uma alimentação adequada e ao repouso.

ARTIGO 8:

a) A experimentação animal, que implica em sofrimento físico, é incompatível com os direitos do animal, quer seja uma experiência médica, científica, comercial ou qualquer outra.

b) As técnicas substutivas devem ser utilizadas e desenvolvidas ARTIGO 9:

Nenhum animal deve ser criado para servir de alimentação, deve ser nutrido, alojado, transportado e abatido, sem que para ele tenha ansiedade ou dor.

ARTIGO 10:

Nenhum animal deve ser usado para divertimento do homem. A exibição dos animais e os espetáculos que utilizem animais são incompatíveis com a dignidade do animal.

ARTIGO 11:

$\mathrm{O}$ ato que leva à morte de um animal sem necessidade é um biocídio, ou seja, um crime contra a vida.

ARTIGO 12:

a) Cada ato que leve à morte um grande número de animais selvagens é um genocídio, ou seja, um delito contra a espécie.

b) O aniquilamento e a destruição do meio ambiente natural levam ao genocídio. ARTIGO 13:

a) O animal morto deve ser tratado com respeito.

b) As cenas de violência de que os animais são vítimas, devem ser proibidas no cinema e na televisão, a menos que tenham como fim mostrar um atentado aos direitos dos animais.

ARTIGO 14:

a) As associações de proteção e de salvaguarda dos animais devem ser representadas a nível de governo. 
b) Os direitos dos animais devem ser defendidos por leis, como os direitos dos homens.

Acabar com os maus-tratos é objetivo internacional e nacional, mesmo na legislação brasileira, eles são banidos, ou seja, as condutas ou atividades consideradas lesivas ao meio ambiente, até mesmo pela pessoa jurídica, pode receber punição. Por isso, de acordo com o art. 225, § 3으, assevera ${ }^{37}$ : "as condutas ou atividades consideradas lesivas ao meio ambiente sujeitarão os infratores, pessoas físicas ou jurídicas, a sanções penais e administrativas, independentemente da obrigação de reparar os danos causados".

O art. 225, § 10, inc. VII, da CF/88 ${ }^{38}$, tutela a integridade animal, afinal, determina a obrigação do Poder Público de proteger a fauna e a flora, o que significa a vedação das práticas que, dentre outras, submetam os animais à crueldade, como acontece quando os animais, expostos por horas a uma jornada exaustiva de peso, não são alimentados, apanham, ficam doentes e não são medicados. As consequências do uso de aparelhos na boca dos animais provocam úlcera, além de prenderem a língua do animal, sem falar das selas e dos arreios. Tais situações são preocupações que estão gerando a conscientização por meio da aprovação de leis que proíbem o uso de cavalos e demais animais como meio de transportes, como a Lei $7.194 / 2016^{39}$.

Segundo Valéria Silva Galdino Cardin e Stela Cavalcanti da Silva, a primeira legislação federal brasileira contra a crueldade dos animais foi o Decreto 16.590 de $1924^{40}$, mas o reconhecimento em Lei, o qual resultou da conscientização em relação ao que é considerado como maus-tratos, ocorreu na sociedade apenas na década de 30. O Decreto-Lei n. 24.645 de 1934, Lei de Proteção dos Animais, que em seu artigo 10 disciplina que todos os animais existentes no país são tutelados do Estado, ou seja, aqui se observa a responsabilidade estatal em relação à proteção passando a inclusive penalizar no artigo segundo os maus-tratos.

O Decreto-Lei n. 24.645 de 1934, em seu artigo 3o, define o que a lei considera como maus-tratos ${ }^{41}$ e são inúmeras as situações contempladas. A medicina veterinária compreende que os animais são seres sencientes, o que significa que eles possuem condições de saber as suas emoções; logo, para que não aconteçam os maus- tratos, é essencial que haja o bem-estar.

O Conselho Federal de Medicina Veterinária, que faz campanha referente ao bem-estar animal para conscientizar as pessoas, defende como indispensável o estabelecimento das condições ideais para todos animais alcançarem o bem-estar. Para a Comissão de Ética, Bioética e Bem-estar animal do CFMV ${ }^{42}$ : 
Um animal com alto grau de bem-estar, segundo a Comissão de Ética, Bioética e Bem-estar animal do CFMV é considerado aquele que tem boa saúde e que pode expressar seu comportamento natural. O comportamento natural de um cão, por exemplo, inclui cavar; o de um porco, fuçar; o de um pássaro voar, e assim por diante.

O art. 40 do mesmo diploma permite a tração animal de veículo; o art. 60 afirma que, para o seu uso nas cidades, são necessários sinais de alarme, mas esses também não podem produzir ruído constante. Percebe-se infelizmente que não apresentam nenhuma solução fática ao problema no trânsito pela ocupação dessas carroças, charretes nas ruas e avenidas, as quais não possuem sinalização apropriada. As normas de trânsito brasileiro classificam esses veículos de (carroças e charretes). ${ }^{43}$ No mesmo diploma, o art. 70 estabelece que a carga por veículos para um determinado número de animais deverá ser fixada pelas municipalidade ${ }^{44}$ e estas necessitam respeitar o peso e espécie de veículo, ou seja, o município é responsável pelas condições desses animais pelo trânsito.

Como o Código Nacional de Trânsito os classificam como veículos é relevante entender as condições e os requisitos de segurança estabelecidos no art. 103 do mesmo diploma. Desse modo, o veículo só poderá transitar pela via quando atendidos os requisitos e condições de segurança estabelecidos neste Código e em normas do Regulamento do Código Nacional de Trânsito o CONTRAN ${ }^{45}$.

No CONTRAN ${ }^{46}$ arts. 38 ao 46, estipulou-se as regras gerais de circulação. Do art. 62 ao 76, houve instruções referentes à sinalização. Do art. 77 ao 91, foram estabelecidas a classificação e normas gerais de uso; inclusive o art. 78 afirma como obrigação de todo veículo, para transitar nas vias públicas, o oferecimento de completa segurança e que esteja perfeitamente equipado, o que não contrasta com a realidade dessas pessoas que infelizmente não possuem as mínimas condições de adequarem as suas carroças ou/e charretes a essas regras.

Também o Código de Trânsito Brasileiro estabelece que, na maioria das vezes, não conseguem alimentar esses animas que acabam ficando doentes, oferecendo riscos. . Ressalva que, mesmo em condições normais de saúde física, esses animais aparecem no meio de avenidas e trânsitos para tumultuar, prejudicar e causar acidentes.

Como se pode verificar, o tema é complexo e envolve vários aspectos, como a questão social, visto que os carroceiros tiram o sustento do material que coletam do lixo. Além disso, tem a questão da saúde dos animais, pois os trabalhadores e as crianças ficam expostos ao mexer no lixo sem nenhuma proteção. Normalmente, o trabalho de catador feito nos contêineres é informal e sem amparo legal. 
As crianças são usadas pelos pais para catar lixo dos contêineres e algumas até conduzem as carroças, situação que afronta os direitos das crianças e que também implica maus-tratos aos animais, porque muitos cavalos são mal cuidados. Em relação aos animais faltam alimentos, medicamentos e alguns donos usam relho para maltratá-los. As carroças dividem espaço com carros, inclusive em horários de picos e até em ruas mais estreitas; desse modo, tanto os carroceiros quanto os motoristas estão expostos a riscos. ${ }^{47}$

As necessidades básicas dos animais não são respeitadas; eles passam por inúmeros sofrimentos, emoções, dores, ansiedades, medos, estresses, ou seja, o controle do carroceiro fere a liberdade deles e também a saúde física, psicológica (tédio na realização de suas atividades, medo e angústia das punições ou das tarefas que encaram ${ }^{48}$ ) e comportamental.

Tais situações comprometem o bem-estar do animal; sendo assim, as consequências podem ser inúmeras, como a redução da expectativa de vida, da habilidade de crescimento, da produção ou reprodução; do aparecimento das lesões corporais, doenças; a imunossupressão; dentre outras, o que, por suposto, alterará todo o processo fisiológico normal e o desenvolvimento anatômico ${ }^{49}$. São comuns as mortes por exaustão durante o trabalho, porque não podem mais trabalhar ${ }^{50}$.

Vânia Tuglio compreende que pela ciência há métodos para a detecção de dores nos animais, por meio de sinais ${ }^{51}$ :

Os sinais fisiológicos e o comportamento sugestivo. Dentre os sinais fisiológicos é de ser ressaltada a ocorrência de midríase na presença da luz, quando o esperado seria a miose. Essa "inversão" é indicativa de reação de alarme presente quando o animal se sente ameaçado, agredido, assustado, com medo ou em pânico. Outro sinal indicativo dessa mesma situação é a taquicardia em razão do aumento da frequência cardíaca, decorrente do maior aporte sanguíneo para os músculos (preparação para a luta ou a fuga). Já o comportamento sugestivo refere-se a movimentos de flexão e extensão dos membros, visando expulsar do corpo o agente agressor.

Assim, as experiências científicas comprovam, por meio do estudo desses sinais, que é possível confirmar as dores ocasionadas por situações que ferem o bem-estar animal, o que gera sofrimento e pode acarretar a morte.

Os animais e a saúde das pessoas que os utilizam muitas vezes também é precária, pois carregam cargas vultuosas, não se alimentam adequadamente, suas jornadas de trabalho são extensas, sem pausas; a maioria não apresenta escolaridade, nem carteira assinada e são pessoas de todas as faixas etárias ${ }^{52}$. 
Os catadores são excluídos da sociedade e ficam marginalizados; a sociedade os tratam como se fossem lixo ${ }^{53}$, por isso, a segregação induz e influencia o modo de tratamento que muitas vezes é dispensando aos animais. Afinal, como já acentuado, a maioria não possui escolaridade que não é um requisito indispensável para exercer essa função, de tal forma que o conhecimento nesse segmento é passado de boca em boca pelos próprios operadores de materiais recicláveis.

A possibilidade de poder inserir o projeto como uma opção para esses operadores é fundamental tanto para os animais quanto para os trabalhadores que muitas vezes estão desempregados, com idade avançada, condição social precária e baixa escolaridade e que por essas circunstâncias não conseguem uma vaga no mercado formal ${ }^{55}$.

O cavalo elétrico é um projeto humanitário que visa melhorar as condições de todos os que estão envolvidos nessa prática de trabalho e o município deve ser o principal incentivador dessa mudança, pois há crescente geração de resíduos e sua destinação inadequada é um grande problema atual, afinal, a atuação do catador junto ao poder público é fundamental para o gerenciamento sustentável e seguro desses materiais. ${ }^{56}$

\section{CAVALO ELÉTRICO: O CARRO DE TRAÇÃO ELÉTRICA}

Os trabalhadores que são catadores de materiais recicláveis necessitam de meios para que possam trabalhar efetivando as funções a eles inerentes; as carroças, as charretes e os carrinhos, na maioria das vezes, são utilizados para carregarem o peso dos materiais recicláveis ou demais materiais. Em boa parte, são conduzidos por equídeos, como exemplo, os cavalos, os quais são responsáveis pelo trajeto muitas vezes extenso e de peso considerável. Além desses, o próprio trabalhador, em alguns casos, é o próprio carregador.

O projeto "Cavalo Elétrico" tem como missão promover o bem-estar tanto do animal quanto das pessoas que carregam esses materiais; trata-se de substituir de maneira sustentável veículos de tração animal. A visão é ser referência regional na -substituição de veículos de tração animal, em que a Empresa Júnior da Universidade Tecnológica do Paraná, que é uma associação sem fins lucrativos e com fins educacionais, formada exclusivamente por alunos do ensino superior ou técnico, e regulamentada pela Lei 13.267/16. A Brasil Júnior (Confederação Brasileira de Empresas Juniores) é o órgão que representa o movimento no âmbito nacional.

O projeto tem o apoio de todos os vereadores de Guarapuava e a colaboração da ACTUS, Empresa Júnior de Engenharia e Consultoria que propôs a elaboração do projeto com um viés sustentável de um veículo de tração elétrica que substitua as carroças tracionadas por animais. A 
partir disso, possa removê-los dos maus-tratos e abusos, além da inclusão social dos profissionais de coleta seletiva, em que se aplica grande parte dos assuntos relacionados à engenharia mecânica, como mecânica dos sólidos, mecânica dos fluídos, projetos mecânicos, liderança e gerenciamento, dentre outros.

A Empresa Júnior elabora projetos de extrema qualidade a um custo reduzido e visa exclusivamente a micros e pequenos empresários, para que se desenvolva também a sociedade; em um projeto de iniciativa pública, que a verba pública possa ser utilizada de maneira otimizada, com a redução de custos e executando mais ações que beneficiem e promovam a sociedade.

O projeto do veículo já consta esboçado e foi apresentado em reunião ${ }^{63}$ com a ACTUS; encontra-se sinalizado, para que ele tenha uma boa sinergia com a cidade quando estiver operando, com faixas sinalizadas e luz de freio; sua dimensão será inicialmente com a largura de 1,3 metros; altura de 1,3 metros; e 1,8 metros de cumprimento. A carga que o veículo poderá suportar será em torno de $600 \mathrm{~kg}$. A bateria terá autonomia de um dia de trabalho e, para realizar o levantamento de sua duração, serão feitas entrevistas com os carroceiros para que se saiba com profundidade as distâncias as quais são percorridas por eles, em média em um dia de trabalho. A velocidade máxima que o Cavalo Elétrico atingirá será em torno de $6 \mathrm{~km} / \mathrm{h}$.

Os vereadores desejam sugerir a substituição dos trabalhadores pelo Cavalo Elétrico para que possa se aprovar o Projeto de Lei, afinal, o outro anteriormente apresentado não fez essa sugestão de substituição e não foi aprovado ${ }^{64}$, afinal, não se pode olvidar que a carroça e as charretes são fontes de subsistência dessas pessoas e a sua proibição traria possíveis impactos sociais e econômicos.

A situação é complexa, pois muitos desses animais acabam doentes; são abandonados ou morrem. A servidora Beatriz Cardoso faz parte da Comissão de Animais Abandonados do Campus. Desse modo, a ACTUS irá desenvolver o projeto para que os vereadores apresentem na Câmara e viabilizem a implantação do Projeto de Lei que busca substituir o uso da Tração Animal pelo protótipo apresentado. Este precisará contar com financiamento externo.

A ideia de um projeto capaz de substituir o uso de carroças, charretes e carrinhos tem como pioneiro o Rio Grande do Sul ${ }^{65}$ e lá recebeu o nome de Cavalo de Lata, a estrutura metálica com carroceria é uma espécie de bicicleta totalmente elétrica, preparada para suportar grandes cargas. O veículo tem suspensão, banco com dois lugares, volante e iluminação completa; usa a carga da bateria por cerca de 60 quilômetros. As peças foram retiradas de motocicletas, em oficinas; o veículo é híbrido, ou seja, ele pode ser movido pelo pedal ou por motor elétrico. Vide imagem: 


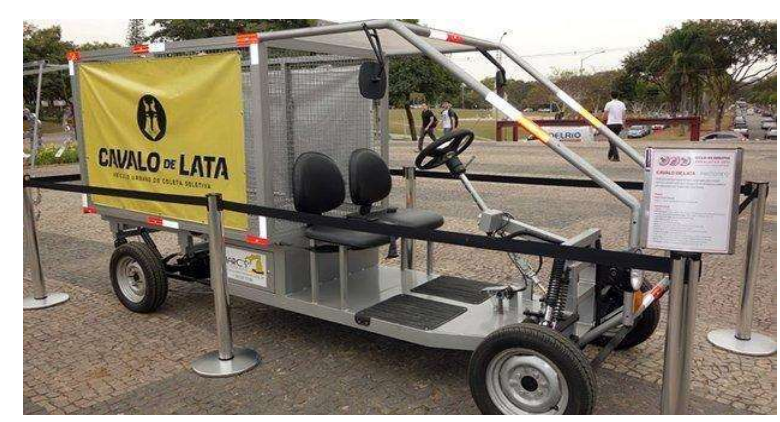

O projeto Cavalo de Lata foi criado pelo engenheiro de produção Jason Duani Vargas., que ficou incomodado com o sofrimento de cavalos que puxam carroças de catadores, em sua cidade, Santa Cruz do Sul (RS). Desenvolveu então um carrinho elétrico de alumínio, o qual tem capacidade para 500 quilos. Diferentemente da carroça tradicional que pode levar até 300 quilos, o carrinho atinge até $25 \mathrm{~km} / \mathrm{h}$. O veículo deve custar R\$20 mil com volante e pedais de acelerador e freio. O engenheiro está negociando a venda do carrinho para cooperativas de catadores de material reciclável e também prefeituras, já que os municípios que incluem catadores na gestão de resíduos passam a ter prioridade na destinação de recursos do governo federal. ${ }^{66}$

O veículo possui luzes de segurança, cintos de segurança nos bancos dos dois passageiros, retrovisores e iluminação. Segundo o engenheiro, o Brasil ainda não possui legislação para veículos elétricos, por isso, não é necessária a carteira de motorista, evidentemente há pesquisadores que entendem que o fato dele ser elétrico não dispensaria o uso da carteira de motorista. No entanto, ele encaminhou o projeto ao Denatran (Departamento Nacional de Trânsito) e aguarda posicionamento do órgão, o que não paralisa os testes e a produção.

No Maranhão67, em São Luís, no mês de maio em 2017, as carroças poderão ser substituídas por carros elétricos. A iniciativa foi proposta pelo programa estadual Mais Renda, do Governo do Maranhão, que destinará os carrinhos elétricos aos trabalhadores de baixa renda que trabalhem com frete de entulho e coleta de lixo, para gerar qualidade de vida e melhores condições de trabalho aos carroceiros da Ilha, além de melhorar o trânsito da cidade.

O projeto é baseado em experiência da organização sem fins lucrativos 'Cavalo de Lata' da cidade de Santa Cruz do Sul, do Rio Grande do Sul que, em parceria com a prefeitura local, que irá alugar os carrinhos para coleta de lixo destinada à reciclagem. Mesmo não havendo data para a implantação em São Luís, a Secretaria de Estado de Desenvolvimento Social (Sedes) cadastrou 540 carroceiros divididos em oito polos da cidade, como São Francisco, Cidade Olímpica e Coroadinho e etc. 
O projeto será testado para tal e se escolherá um dos polos das cidades com a distribuição de carrinhos elétricos. A fase experimental inclui a instalação de um galpão com prensa para reciclagem de lixo em local estratégico do polo escolhido. Trata-se de carro elétrico movido à bateria recarregável em tomada simples, com autonomia para percorrer 60 quilômetros e capacidade para transportar $500 \mathrm{~kg}$, em que o custo por quilômetro percorrido gira em torno de $R \$ 0,02$ a $R \$ 0,05$. Ou seja, economicamente viável e de importância social e ambiental; substituições que são realidade no nosso país, como demonstram os carrinhos elétricos que substituíram os cavalos na ilha da Paquetá no Rio de Janeiro ${ }^{68}$.

\section{ADMINISTRAÇÃO PÚBLICA COMO PRINCIPAL EFETIVADORA DO PROJETO “CAVALO ELÉTRICO”}

A administração pública será a principal efetivadora do presente projeto em Guarapuava, mas nada impede que as cooperativas e os particulares também adquiram o carrinho elétrico. A ideia da ACTUS e dos vereadores de Guarapuava é que o preço seja acessível para que possa se efetivar a possibilidade de substituição dessas carroças, charretes e carrinhos pelo carrinho elétrico.

Uma das preocupações é a relativa ao preço considerando que os trabalhadores apresentam pouco poder aquisitivo, assim sendo, deve ser acessível, como foi observado na recente notícia da compra desses carrinhos no Maranhão ${ }^{69}$, por meio da proposta do programa estadual Mais Renda, do Governo do Maranhão, para que os trabalhadores de baixa renda possam ter a garantia de melhores condições de trabalho, o que consequentemente garantirá e protegerá os Direitos Humanos e os Direitos dos Animais.

Como observado o projeto pode ser executado em cidades brasileiras, desse modo, a responsabilidade pelo desenvolvimento e execução do projeto deve ser considerada, assim, na cidade de Guarapuava, caberá ao município sua execução, o qual possui autonomia política administrativa e financeira, que juridicamente é uma entidade com personalidade jurídica de direito público interno dividido em dois poderes, o legislativo e o executivo; o primeiro com sede na câmara municipal; o segundo, na prefeitura municipal. Na câmara, os membros do poder legislativo, a chefia dos poderes legislativo compete ao presidente da câmara. ${ }^{70}$

O Poder Executivo municipal tem como chefe o prefeito e desempenha as funções por meio de um aparelho administrativo que é constituído por órgãos como as secretarias, os departamentos, os serviços, dentre outros, além entidades, como as autarquias, as fundações e 
as empresas estatais, cuja configuração se orienta segundo as especificidades locais em termos de necessidades de oferta de bens e serviços públicos. ${ }^{71}$

Na gestão, segundo Les Metcalfe ${ }^{72}$ e Richards, assumem as responsabilidades para o funcionamento de um sistema; a responsabilidade é um atributo essencial da gestão. Para os doutrinadores, uma das possíveis definições de gestão é conseguir que determinadas tarefas sejam realizadas por terceiros, em que o indivíduo ou um grupo deve ser investido com o direito e a obrigação de velar pela coordenação dos esforços são indispensáveis para o emprego os programas de ação governamental.

Segundo $\mathrm{BUCCl}^{73}$, as políticas públicas são os programas de ação governamental que visam coordenar os meios à disposição do Estado e as atividades privadas, para a realização de objetivos socialmente relevantes e politicamente determinados. Desse modo, o emprego do projeto "Cavalo Elétrico" é visto como programa de ação governamental em outros estados e pode ser aplicado em Guarapuava e em todo Estado do Paraná. Por isso, assim como, a administração pública municipal de outros Estados o utilizam como instrumento eficiente, cabe ao Município de Guarapuava, que inclusive conta com apoio da câmara dos vereadores e da UTFR. Esta, por meio da ACTUS, apresentou projeto e está construindo protótipos que visam dar a possibilidade de substituição para os operadores recicláveis melhorando a vida deles e a condição dos animas empregados nessa prática.

\section{CONSIDERAÇÕES FINAIS}

O presente artigo tem o objetivo de comprovar a viabilidade do empregado do projeto "Cavalo Elétrico" para substituir carroças, charretes e carrinhos que os catadores utilizam para concretizar o desenvolvimento sustentável que é garantia do meio ambiente para as futuras gerações, por meio da inclusão social dessas pessoas na sociedade. Isso consequentemente melhorará a condição do trabalho delas e a proteção dos animais não humanos, os quais são sujeitos de direitos por meio da implementação de programas de ação governamental da administração pública. 
Os operados de materiais recicláveis, vulgarmente conhecidos como catadores, muitas vezes utilizam do próprio corpo, quando eles mesmos carregam as toneladas em carrinhos; ou quando usam animais nas carroças e charretes que são responsáveis pelo carregamento, isso tudo traz sérias consequências à saúde humana e a dos animais, por causa desses excessos.

A proclamação dos Direitos dos Animais positivou que todo animal possui direitos, os quais, quando não respeitados, incorrem em crimes, já que os animais têm o direito à vida digna. Desse modo, não se pode exterminá-los, explorá-los, o que veda a sua submissão aos maus- tratos e atos cruéis.

Para poder cumprir essas garantias da Declaração dos Direitos dos Animais, a legislação constitucional e infraconstitucional, tornou-se indispensável que se possa estabelecer um ambiente capaz de proporcionar o bem-estar por meio da realização de suas necessidades básicas para que as condições desfavoráveis a que eles são submetidos não venha a inseri-los a maustratos.

O projeto de lei que será apresentado na câmara municipal de vereadores da cidade de Guarapuava propõe a possibilidade de substituição do uso do "Cavalo Elétrico" que protegeria os Direitos dos Animais e os Direitos Humanos, pois haverá a disponibilização de veículos automotores recarregáveis por meio de bateria, com estrutura apta para carregar até $600 \mathrm{~kg}$ de materiais, para os quais, não são necessárias o uso de carteiras de motoristas, já que o limite de velocidade é de $6 \mathrm{~km} / \mathrm{h}$ e o trabalhador ficaria ao lado do protótipo. Esses carrinhos seriam distribuídos pela Prefeitura de Guarapuava em condições plenas e que receberiam a devida manutenção e sinalização.

O emprego de programas de ação governamental está sendo realizado com êxito em outros estados, como visto no trabalho. Assim, poderá ser aplicado em Guarapuava e em todo Estado do Paraná, afinal, conta com o apoio da câmara dos vereadores e da UTFR que, por meio da ACTUS, está construindo protótipos que visam dar a possibilidade de substituição para os operadores recicláveis, o que consequentemente produzirá a melhoria de vida desses trabalhadores e garantirá a promoção e o respeitos dos direitos dos animas.

\section{REFERÊNCIAS BIBLIOGRÁFICAS}

BARONI, Margaret. Ambiguidade e deficiências do conceito de desenvolvimento sustentável. Revista de Administração de Empresas. v. 32. n. 2. p. 14-24. Disponível: << http://www.scielo.br/pdf/rae/v32n2/a03v32n2.pdf>> Acesso: 1 ago. 2017. 
BEHLING, Greice Maia; CAPORLINGA, Vanessa Hernandez. Animais como sujeitos de direito: Contribuição da educação ambiental transformadora. XVI Encontro Paranaense de Educação Ambiental. Disponível: <<http://www.epea2017.ufpr.br/wpcontent/uploads/2017/05/749-E2S4-ANIMAIS-COMO-SUJEITOS-DEDIREITO.pdf>>Acesso: 2 ago. 2017

BRASIL. CONSTITUIÇÃO DA REPÚBLICA FEDERATIVA DO BRASIL DE 1988.

Disponível: <http://www.planalto.gov.br/ccivil_03/constituicao/constituicaocompilado.htm>. Acesso: 24 jul. 2017.

BRASIL. Lei 9.605/1998. Disponível:

<http://www.planalto.gov.br/ccivil_03/leis/L9605.htm>. Acesso: 24 jul. 2017

BRASIL. Constituição Federal de 1988. Disponível: < http://www.planalto.gov.br/ccivil_03/constituicao/constituicaocompilado.htm> Acesso: 31 ago 2018

BUCCl, Maria Paula Dallari. O conceito de política pública em direito. Políticas públicas: Reflexos sobre o conceito jurídico. Maria Paula Dallari Org. São Paulo: Saraiva, 2016. p. 38-39

CARDIN, Valéria Silva Galdino; SILVA, Stela Cavalcanti da. Do reconhecimento dos direitos dos animais não humanos na família pluriespécie no direito brasileiro. UFBA. Revista brasileira de direito animal. $\quad$ v. $11 . \quad$ n. $23 . \quad$ Disponível: $<$ https://portalseer.ufba.br/index.php/RBDA/article/view/20345>>. Acesso: 7 ago. 2017

CONSELHO FEDERAL DE MEDICINA. Disponível: $<$ http://portal.cfmv.gov.br/portal/pagina/index/id/150/secao/9>> Acesso: 8 ago. 2017

\section{DECLARAÇÃO DE ESTOCOLMO.}

$<$ <ttp://www.direitoshumanos.usp.br/index.php/Meio-Ambiente/declaracaosobre-o-ambiente-humano.html> Acesso: 01 jul. 2017.

DECLARAÇÃO UNIVERSAL DOS DIREITOS DOS ANIMAIS-UNESCO. 
Disponível:

<http://www.urca.br/ceua/arquivos/Os\%20direitos\%20dos\%20animais\%20UNESCO.p

$d f>$ Acesso: 7 ago. 2017

DECRETO no 24.645, de 10 de julho de 1934. Disponível: $<$

http://funed.mg.gov.br/wp-content/uploads/2010/05/Decreto-lei-24645-34-maustratosanimais.pdf> Acesso: 8 ago. 2017

DIÁRIO DE SANTA MARIA. Caminho cruzado entre cavalo e o carroceiro. Disponível<<https://diariodesantamaria.atavist.com/caminho-cruzado-entre-cavaloecarroceiro>> Acesso: 8 ago. 2017

ESTEVES, Rafael Alves. A indústria do resíduo: Panorama das cooperativas de reciclagem e dos catadores de resíduos no estado do Rio de Janeiro. Revista monografias ambientais. Santa Maria. Revista do Centro de Ciência Naturais e Exatas. UFMS. v. 14., n. 2., mai-ago, 2015., p. 91

GOLDIM, José Roberto. Notas sobre bioética e medicina veterinária. Universidade Federal do Rio Grande do Sul. Disponível: $\quad<$ https://www.ufrgs.br/bioetica/medvet.htm>> Acesso: 8 ago. 2017

INSTITUTO DE ECONOMIA APLICADA. IPEA. Situação social das catadoras e dos catadores de material reciclável e reutilizável - Brasil. p. 42 Disponível:

<<http://www.ipea.gov.br/portal/images/stories/PDFs/situacao_social/131219_relatorio _situacaosocial_mat_reciclavel_brasil.pdf >> Acesso: 23 jul. 2017

KLERINGA, Luis Roque; BERGUEB, Sandro Trescastro; SCHROEDERC, Christine da Silva; PORSSED, Melody de Campos Soares; STRANZE, Eduardo; KRUELF, Alexandra Jochims. Competências, papéis e funções dos poderes municipais no contexto da administração pública contemporânea: Poderes, funções e funções das autoridades municipais dentro do contexto Da administração pública contemporânea. Análise a revista acadêmica da Face. Porto Alegre, v. 22, n. 1, p. 31-43, jan./jun. 2011.

Disponível: 
<<http://revistaseletronicas.pucrs.br/ojs/index.php/face/article/viewFile/9778/6701>> Acesso: 8 ago. 2017

MEDEIROS, Luiza Ferreira Rezende de; MACEDO, Katia Barbosa. Catador de material reciclável: Uma profissão para além da sobrevivência?. Psicologia \& Sociedade. v. 18. Maio-Ago. 2006. p. 6364.

MINISTÉRIO DO TRABALHO. CBO. Instituída por portaria ministerial №. 397, de 9 de outubro de 2002, a qual tem por finalidade a identificação das ocupações no mercado de trabalho. Disponível: <http://www.mtecbo.gov.br/cbosite/pages/home.jsf> Acesso: 23 jul. 2017

NAKO, Georgete Nacarato; MUKAI, Toshio. O direito ambiental no Brasil: Evolução histórica e a relevância do direito internacional do meio ambiente. Revista de Direito Administrativo. v. 226. Rio de Janeiro. Jan. Mar./2001. p. 75-103.

Disponível: < http://bibliotecadigital.fgv.br/ojs/index.php/rda/article/viewFile/48313/46493> Acesso: 01 ago. 2017.

NASCIMENTO, Elimar Pinheiro do. A trajetória da sustentabilidade: Do ambiental ao social, do social ao econômico. Revista de Estudos Avançados da USP. 26 (74), 2012. p. 1. Disponível: < http://www.revistas.usp.br/eav/article/view/10624/12366> Acesso: 26 jul. 2017

NOTÍCIA. Disponível: <http://publico.uol.com.br/ecosfera/noticia/humanidadeatingequartafeira-limite-de-recursos-disponiveis-no-planeta-terra-1780971> Acesso: 1 ago. 2017

NOTÍCIA. Disponível: < http://publico.uol.com.br/ecosfera/noticia/humanidadeatingequartafeira-limite-de-recursos-disponiveis-no-planeta-terra-1780971> Acesso: 1 ago. 2017

NOTÍCIA. Disponível: <https://oglobo.globo.com/rio/lei-proibe-uso-de-cavalospara-puxarcarrocas-no-estado-18447169>> Acesso: 7 ago. 2017

NOTÍCIA. Disponível:< http://www.animal-ethics.org/exploracao-animal/animaistrabalhadoresintroducao/animais-usados-trabalhadores> Acesso: 6 nov. 2017. 
NOTÍCIA. Disponível:

<http://gmaisnoticias.com/noticias/07_12_2016_projeto_que_pro_iacutebe_ve_iacutecu los_movidos_agrave_tra_ccedil_atildeo_animal_n_atildeo_eacute_aprovado_pela_c_ acircmara_de_vereadores.htm> Acesso: 25 jul. 2017

NOTÍCIA. Disponível: <http://www.hypeness.com.br/2013/09/projeto-substituicavalos-deverdade-por-veiculo-sustentavel-feito-de-lata/> Acesso: 25 jul. 2017.

NOTÍCIA. Disponível:

<https://economia.uol.com.br/empreendedorismo/noticias/redacao/2013/10/03/engenh eirocria-carroca-eletrica-para-catador-de-reciclaveis-e-funeraria.htm>Acesso: 25 jul. 2017.

NOTÍCIA. Disponível:<http://www.ma.gov.br/agenciadenoticias/desenvolvimento/governo-domaranhaoestuda-substituir-carrocas-a-tracao-animal-por-carros-eletricos-em-sao-luis> Acesso: 25 jul. 2017.

NOTÍCIA. Disponível: < https://oglobo.globo.com/rio/carrinhos-eletricos-estreiamno-lugar-decharretes-na-ilha-de-paqueta-19354726> Acesso: 25 jul. 2017.

OLIVEIRA, Liliane Martins de; MARQUES, Renata Leal; NUNES, Carlos Henrique; CUNHA, Ana Maria de Oliveira. Carroceiros e equídeos de tração: Um problema sócio-ambiental. Revista Caminhos de Geografia. v. 8. n. 24. Dez. 2007. p. 204-216.

OLIVEIRA, Liliane Martins de; MARQUES, Renata Leal; NUNES, Carlos Henrique; CUNHA, Ana Maria de Oliveira. Carroceiros e equídeos de tração: Um problema sócio-ambiental. Revista Caminhos de Geografia. v. 8. n. 24. Dez. 2007. p. 204-216.

PINHEL, Julio Ruffin. O catador de materiais recicláveis. Do lixo à cidadania: Guia para a formação de cooperativas de catadores de materiais recicláveis. IPESA. p.30 Disponível: <http://www.dolixoacidadania.org.br/construcao/pdf/DOLIXOACIDADANIA.pdf> Acesso: 8 ago. 2017 
REGULAMENTO DO CÓDIGO NACIONAL DE TRÂNSITO. Disponível:

<http://www.planalto.gov.br/ccivil_03/decreto/antigos/D62127.htm> Acesso: 8 ago. 2017

REGULAMENTO DO CÓDIGO NACIONAL DE TRÂNSITO. Disponível:

<http://www.planalto.gov.br/ccivil_03/decreto/antigos/D62127.htm> Acesso: 8 ago. 2017

SOUZA, Mariângela Freitas de Almeida. Implicações para o bem-estar de equinos usados para

tração de veículos. Revista de Direito Animal. Disponível: « https://portalseer.ufba.br/index.php/RBDA/article/view/10247/7304>> Acesso: 6 nov. 2017. p. 191-198.

TUGLIO, Vânia. Espetáculos públicos e exibição de animais. Revista de Direito Animal. Disponível: < https://portalseer.ufba.br/index.php/RBDA/article/view/10250/7307〉> Acesso: 6 nov. 2017. p.235.

Trabalho enviado em 20 de janeiro de 2019

Aceito em 03 de fevereiro de 2020 